\title{
Using Experimental and Artificial Intelligence Techniques forPrediction of the Sedimentation at Lateral Intakes
}

\author{
Ahmed, S.T.*, M. Soliman \\ Faculty of Engineering, Cairo University, Jiza, Egypt \\ Email address: \\ Samirtaher1981@yahoo.com (Ahmed, S.T.), soliman136@gmail.com (M.Soliman) \\ *Corresponding author
}

\begin{abstract}
:
The main use of the lateral intakes is water conversion from a main channel into a branch channel for different purposes such as water distribution network, irrigation and cooling systems at thermal power plants. The flow structure at the intake is very complicated due to sediment diversions. The intake usually installed making a right angle with the main channel flow direction, it have been noticed that the right-angle intakes produce a large sediment diversion and reduce flow rate inside the intake. Thus, the optimum angle of an intake is very important to minimize sediment volume at the intake channel and to maximize flow rate. Therefore, a physical model utilized to investigate the different obtuse angle of the intake. Five different intake angles $\left(110^{\circ}, 130^{\circ}, 145^{\circ}, 160^{\circ}\right.$ and $\left.170^{\circ}\right)$ investigated for the lateral intake with different flow ratios. For further investigation sensitivity and parametric analysis using LSL and ANN-based models applied to experimental results. Analysis of experimental results showed that the intake angle $160^{\circ}$ gives better results compared to other intake angles. In addition, the results indicated that the separation zone vanishes at the highest flow
\end{abstract}


discharge ratio at both the intake angle of $160^{\circ}$ and $170^{\circ}$.LSL results found that the diverted sediment $\mathrm{S}_{\mathrm{vr}}$ is most sensitive to the intake angle with $55.3 \%$ influence, followed by the discharge ratio with about $40.2 \%$ and by the width ratio with about $4.5 \%$. Two ANN-based models were developed using the experimental results combinations from the most influential parameters on the sediment ratio diverted to the lateral intake $\left(\mathrm{S}_{\mathrm{vr}}\right)$ and contraction coefficient (Cc). The ANN models for predicting Svr and $C c$ performed well with an average $\mathrm{R}^{2}$ of 0.98 . The error measures, RMSE shows low values.

From analysis, the optimum lateral intake angle is $164^{\circ}$. Also, the intake angles range 150 to 170 we can neglect effect the width ratios.

Keywords: lateral intake, intake angles, sediment volume, sediment diversion, ANN-based models.

\section{Introduction}

Lateral intakes used to divert flow from a main channel into a branch channel for purposes of irrigation, water supply and cooling system for thermal power plant. Sediment transport is a key issue while discussing lateral intakes performance. Diverted sediment has been the subject of interest for researchers and hydraulic engineers for many decades. The aim of hydraulic engineers while designing an intake is the water deflected by the lateral intake has maximum flow discharge and minimum sediment volume. Sediments may have transported into intakes and deposited at different parts inside the lateral intakes. In addition, the lateral intake channel' discharge capacity will be affected because of the sedimentation process. In case of high flow velocity, turbo machines such as pump and turbine systems suffer from damage due to passing suspended particles through its intake.

Rough materials could lead to erosion of the channel walls. In addition, sedimentation facilitates the conditions for vegetation growth, which increases channel flow resistance.

The study of flow phenomena in front of the lateral intake channel has attracted the attention of researchers such as full knowledge of the diversion flow pattern is a necessary condition to study the intake sediments. (Taylor 1944) was the first to study the flow pattern in the right angle of the intake channel and proposed a graphical method for determining the twodimensional flow patterns. Also, (Neary and Odgaard 1993) studied the right intake angle 
and stated "separation zone and the secondary current varied from the bed to the water surface".

The first developed and validated numerical method for modeling 3D lateral intake flows was that of (Neary "et al." 1999), which stated, "The diversion flows are essentially 3dimensional". Some features of them are represented in Figure. 1.

As the flow approaches close to the intake channel, it accelerated laterally due to the suction pressure at the end of the side intake channel. The acceleration divides the flow into two parts, a portion enters the intake channel, and the other continues to the downstream in the main channel as illustrated in Fig. 1 [6]. The former illustrated in Fig. 1 by surface called the Dividing Stream Surface (section 2-2). In the rectangular main channels, the diversion flow width at the bed is greater than that in the surface, which reasons the sediments entry into lateral intake, resulting from their high density in the bed. The stream wise curvature in the dividing stream surface yields imbalance among forces; the transverse pressure gradient, shear force and centrifugal force. Consequently, a secondary current in a clockwise direction formed. Another secondary current also formed along the main channel wall. The more these current advances toward downstream, the more reduces its strength primarily due to the fluid viscosity. The secondary current besides the separation zone along the inner wall of the lateral channel (Zone A) gives rise to a complex three-dimensional flow. The extent of dividing stream surface in the main channel determines the rate of flow and sediment discharge to the lateral channel.

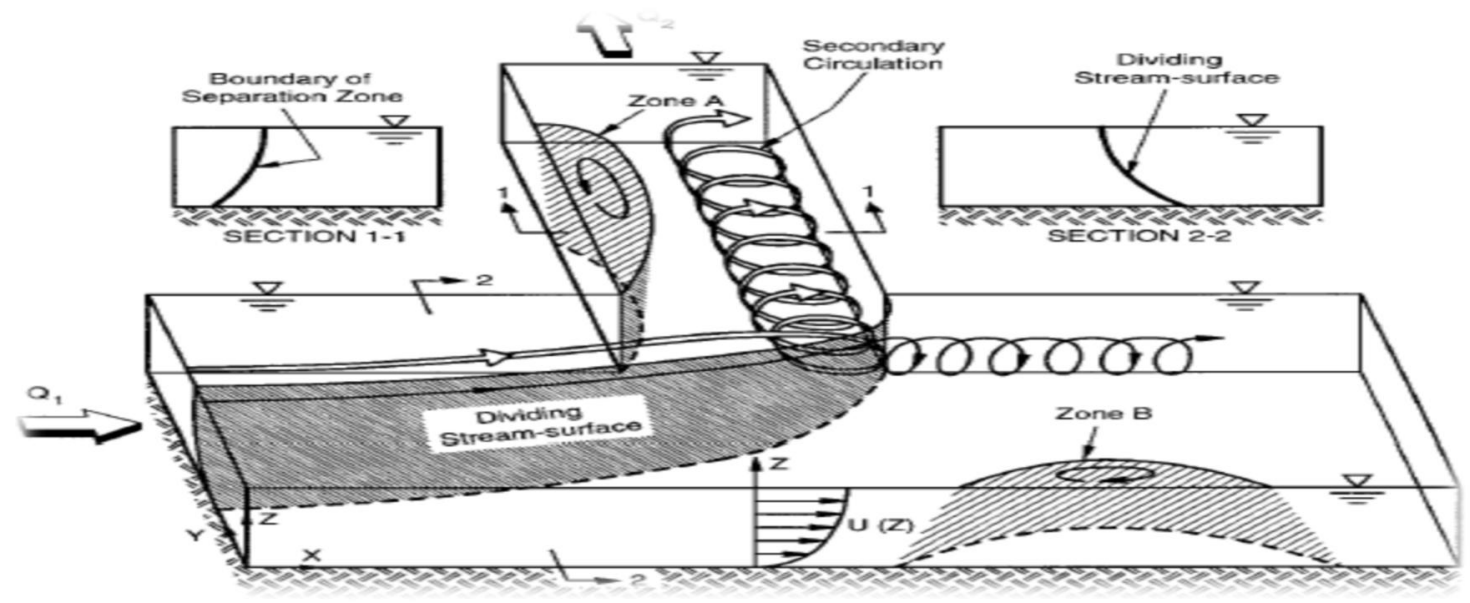

Figure. 1. The flow pattern in the intake entrance, (Neary et.al, 1999)

In the past decades many researchers studied the diversion angle of the lateral intake and effect it on the control the flow in diversion and sediment volume inside the intake channels. 
Angle of Diversion is the angle of deflection between the direction of flow in the main channel and the direction of flow in the lateral intake as illustrated in Fig 2. (Egyptian Engineers 1949) stated, "The angle of diversion is considered an effective factor on sediment diversions into the intake channel", (Vanoni 2006).

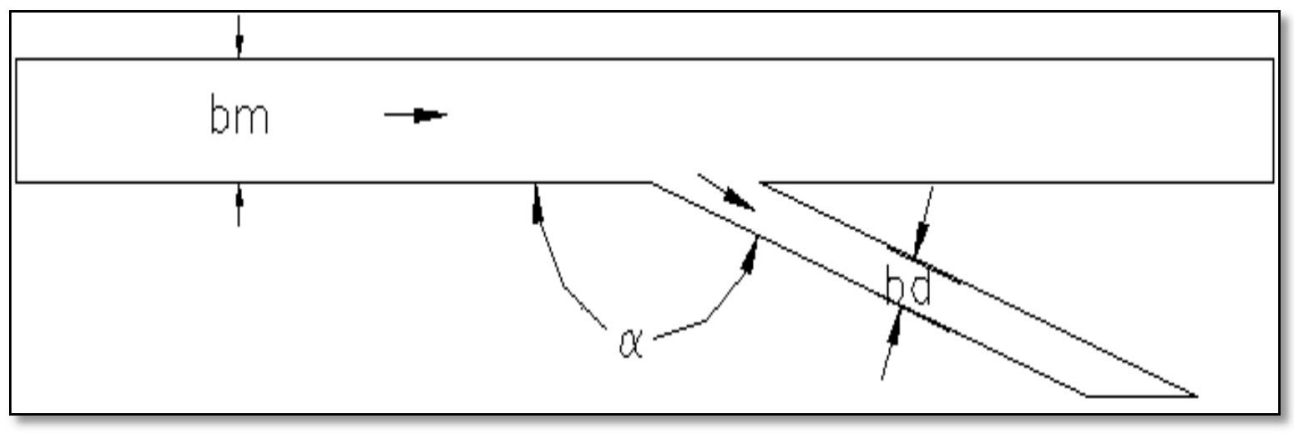

Fig. 2 the diversion angle ( $\alpha$ ) of the lateral intake

(Vanoni 2006) mentioned that "H. Bulle (1926) and A. Schoklitsch (1937) studied the intake angle and stated that there is nothing called optimum angle for the intake channel because this angle would vary with discharge ratio and the location of intake. For a given angle the best solution to the problem is to probably select the diversion angle by the model study for dominant discharge ratio".

(Razvan E. 1989) defined the best diversion angle (between the main channel and the lateral intake) to be between $95^{\circ}$ and $120^{\circ}$. (Novak 1990) stated that the worse angle for water intake is right angle. Also, (Arved J. Raudkivi1993) recommended that an optimum angle for minimum sediment diversion to be $105^{\circ}-110^{\circ}$.

(Amin, A., 2005) investigated experimentally the velocity distributions at intake channel using a fixed-bed model. He studied the effect of the diversion angles on enhancing the flow pattern at channel intake. The experimental results showed that the recommended range of the diversion angle of the channel intake needed to enhance the flow pattern inside the channel intake is in the range of $100^{\circ}$ to $112^{\circ}$.

(Afrouz A. 2016) used numerical modeling only. This study revealed that increasing diverting angle might cause separation zone decreased normally and stated "Separation zone is narrowing and shorting with increasing diverting angle".

Previous researches carried out for studying separation zone and sediment diversion at the right angle revealed that at a right-angle intake, a large separation zone occurs and high 
sediment diversions. Few studies done to understand flow separation only inside the intake channel with different angles.

This paper is devoted to experimentally study the effect of width ratios $(0.3,0.4,0.5$ and 0.6$)$ (lateral channel bed width / main channel bed width) with lateral intake angels of $110^{\circ}, 130^{\circ}$, $145^{\circ}, 160^{\circ}$ and $170^{\circ}$ installed on a rectangular channel on the flow characteristics and the diverted sediment to achieve maximum flow discharge with minimum diverted sediment.

\section{Experimental Setup and Methodology}

To study the flow pattern and the diverted sediment to intakes, the experiment reported herein conducted in a recirculation flume inside the Northern experimental hall of the Hydraulics Research Institute (HRI), Egypt.

The channel consists of five main parts; head and tail tanks, main and lateral channels and bypass channels. Two centrifugal pumps are used; the first one is to supply water to the head tank from the underground sump, while the other one is at the end of the lateral channel to deliver water to the bypass channel. Water flow controlled using a control valve installed on the pipe connected to the feeding pump. The head tank has a weir and a gravel box. The weir is calibrated to measure the outflow which feeds the main channel, while the gravel box is used to provide an even flow distribution across the main channel. The flow enters the main channel through an inlet screen to dump the oscillations in the water surface. All tanks are brick built, sealed with cement mortar and covered with a non-porous material as illustrated in Figure.3. 


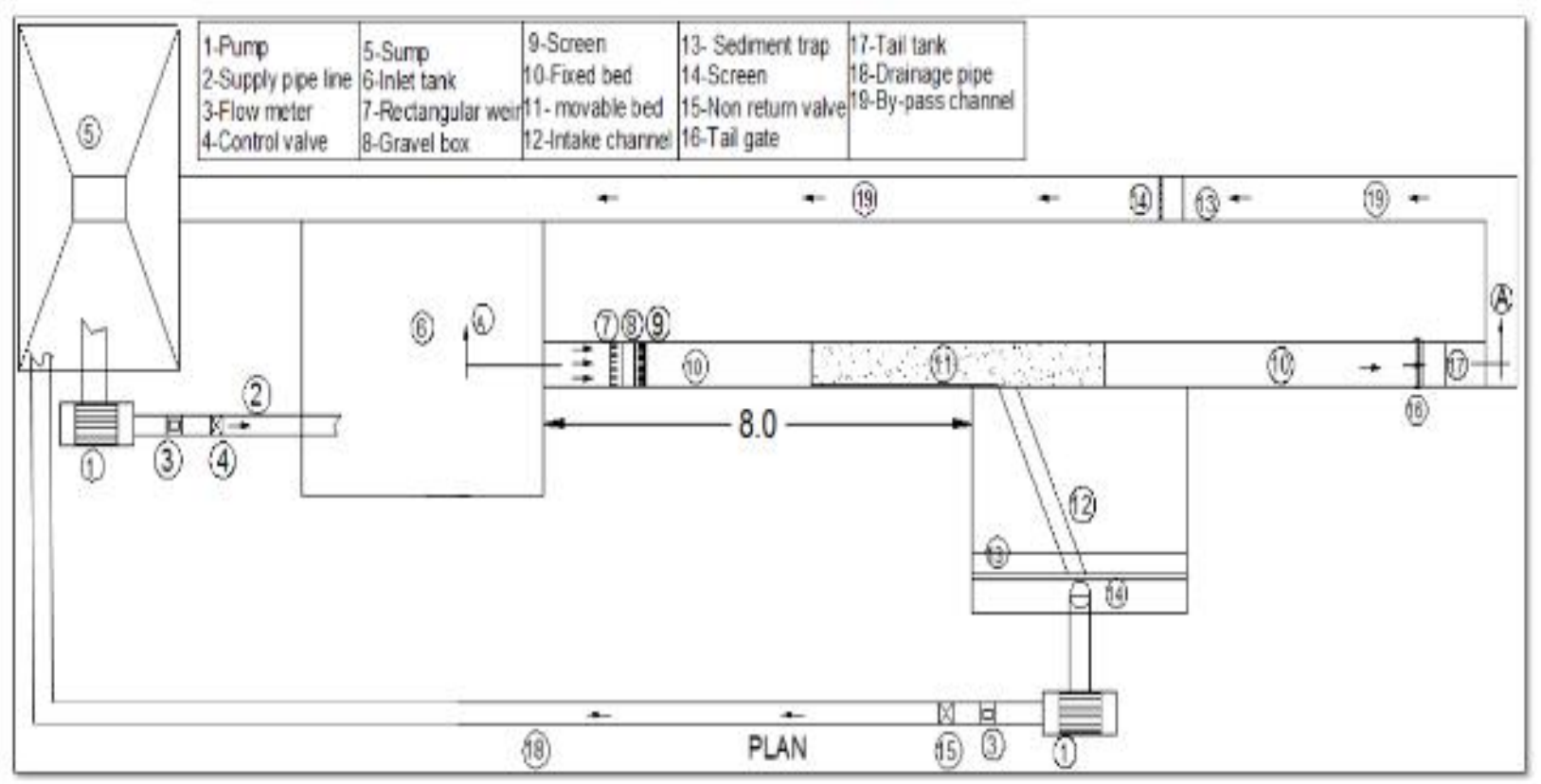

Figure.3. The Experiment Setup in Plan

The model is constructed using smooth cement-sand mortar overlaid on a layer of sand of 0.5 $\mathrm{m}$ thick. To represent the movable bed, the movable material is scattered on the main channel bed, which extended $3.0 \mathrm{~m}$ upstream and $2.50 \mathrm{~m}$ downstream the intake of the lateral channel respectively.

The experiment is composed of the main channel which has a rectangular section with $0.6 \mathrm{~m}$ width, $20.0 \mathrm{~m}$ length and $0.60 \mathrm{~m}$ depth together with a lateral channel which has a rectangular section with variable width $(0.18,0.24,0.3$ and $0.36 \mathrm{~m}), 3.0 \mathrm{~m}$ length and $0.6 \mathrm{~m}$ depth .

The lateral channel is set at eight meters from the entrance of the main channel with variable obtuse angles $110^{\circ}, 130^{\circ}, 145^{\circ}, 160^{\circ}$ and $170^{\circ}$. A tailgate located at the downstream end of the main channel controls the tail water depth.

The movable bed material is Polyvinyl Chloride (PVC) with a thickness of $0.15 \mathrm{~m}$. The used PVC has a specific gravity of $1080 \mathrm{Kg} / \mathrm{m}^{3}$ and $\mathrm{D}_{50}$ of $2.5 \mathrm{~mm}$. This material is chemically inert so that it does not react with eventual actions in water and it does not have electrostatic nature as well. A precise point gauge installed to measure the bed level and the water depth.

The fixed floor elevation of the intake leveled with a movable bed in the main channel. The intake channel has a sediment collection trap followed by a screen to collect the bed material. To study the influence of the intake angle on sediment diversions inside the lateral channel, main channel flow kept constant at $25 \mathrm{Lit} / \mathrm{sec}$ as the tailgate closed completely and the backwater started to fill the flume until reaching a depth higher than the required water depth. 
Then, the pump of the main channel switched on and the upstream feeding start whereas, the required discharge of the main channel controlled by the control valve and measured by Ultrasonic Flow Meters with accuracy $\pm 1 \%$.

While four discharge ratios $\left(\mathrm{Q}_{\mathrm{r}}=0.10,0.20,0.30\right.$ and 0.40$)$ with width ratios $\left(\mathrm{B}_{\mathrm{r}}=0.3,0.4\right.$, 0.5 and 0.6 ) are considered for the lateral channel, where the pump of the lateral intake channel is switched on and the required discharge of the lateral intake channel is controlled with using the control valve and measured by ultrasonic flow meter. The tail water depth $\left(\mathrm{y}_{\mathrm{t}}\right)$ at the end of the main channel is fixed to be equal $0.14 \mathrm{~m}$.

Twenty runs conducted including four runs for each intake angle. For each run backwater feeding is started first until the depth reaches more than the required downstream depth $\left(\mathrm{y}_{\mathrm{t}}\right)$, Then, upstream feeding starts to adjust the depth of tail water and the tailgate is screwed gradually until the required depth is reached. Several trials conducted to find the optimum run duration. Two-hour duration is the best duration for sediment movement, so that it kept fixed for all runs under consideration. Flow velocity measured using an electromagnetic current meter with accuracy $\pm 1 \%$ of the measured value. To clarify and compare between different intake angles and their effects on the separation zone, an examination of length and width of separation carried out by permanganate powder, current meter and wire inside the intake channel as illustrated in Figure. 6. Separation zone defined by the area of reduced pressure and re-circulating fluid with low velocities. Therefore, it has a strong sediment deposition potential in which sediment particles enter the intake channel.
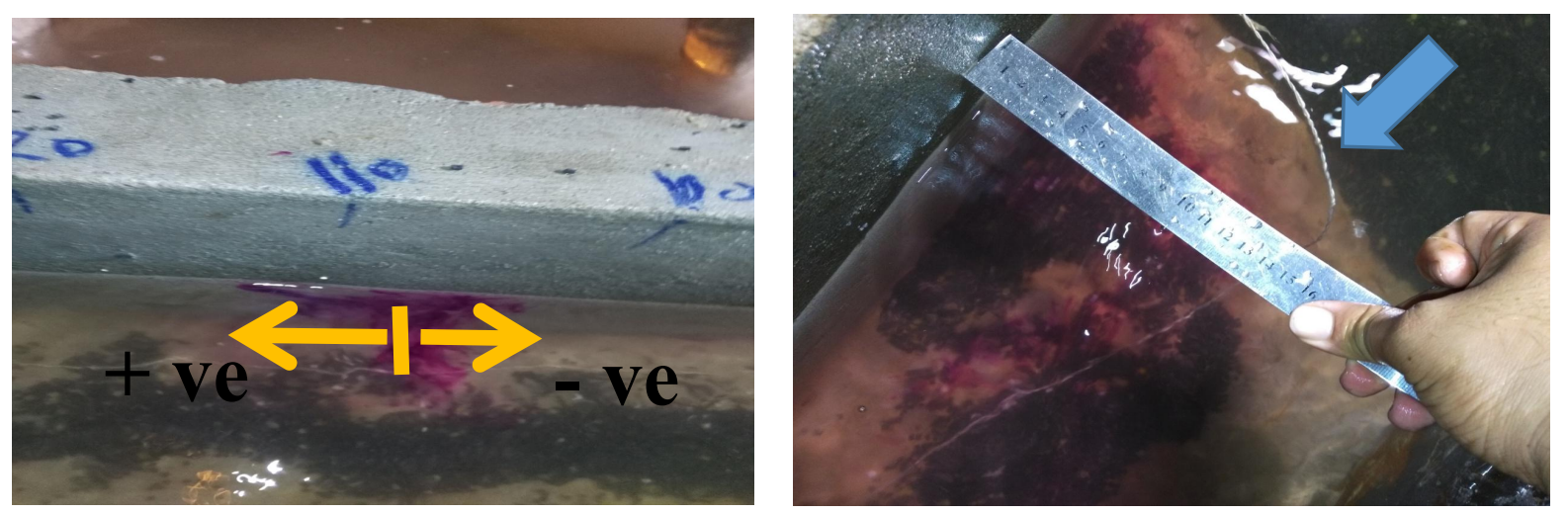

Fig. 4. Determination of separation zone

By the end of each run, the flume emptied and the volume of sediment that entered the lateral channel measured. A squared beaker (of $0.168 \mathrm{~m} \times 0.168 \mathrm{~m} \mathrm{x} 0.82 \mathrm{~m}$ ) used to measure the sediment volume. The working part recorded with precision point gauge to monitor the bed 
topography on a grid of $0.2 \mathrm{~m}$ size in the transversal direction and $0.1 \mathrm{~m}$ in the longitudinal direction to estimate the maximum scour depth beside intake.

\section{Results and Analysis}

From dimensional analysis, the following dimensionless groups illustrate the influence of the intake angle on the diverted sediment and flow characteristics

$$
\mathrm{S}_{\mathrm{v}} / \mathrm{S}_{\mathrm{vt}}, \mathrm{d}_{\mathrm{s}} / \mathrm{y}_{\mathrm{t}}, \mathrm{L}_{\mathrm{s}} / \mathrm{y}_{\mathrm{t}}, \mathrm{w}_{\max } / \mathrm{y}_{\mathrm{t}}, \mathrm{Cc}, \mathrm{Q}_{\mathrm{r}}, \mathrm{B}_{\mathrm{r}}, \mathrm{F}_{\mathrm{r}}
$$

Where:

The ratio between sediment volume diverted to the lateral channel and the $\mathrm{S}_{\mathrm{v}} / \mathrm{S}_{\mathrm{vt}} \quad$ sediment column volume where it represents a square beaker whose dimensions are $(0.168 * 0.168 * 0.82) \mathrm{m}$

The ratio between the maximum scour beside the outer wall of the intake and the $\mathrm{d}_{\mathrm{s}} / \mathrm{y}_{\mathrm{t}} \quad$ water depth

$\mathrm{L}_{\mathrm{s}} / \mathrm{y}_{\mathrm{t}} \quad$ The ratio between the separation length and the water depth

$\begin{array}{cl}\mathrm{w}_{\max } / \mathrm{y}_{\mathrm{t}} & \text { The ratio between the maximum separation width and the water depth } \\ \mathrm{Cc} & \text { The ratio between effective width of lateral intake and width of the intake }\end{array}$

$\mathrm{Q}_{\mathrm{r}} \quad$ The ratio between the diverted flow discharge to the total flow discharge

$\mathrm{B}_{\mathrm{r}} \quad$ The ratio between the branch channel width to the main channel width

$\mathrm{F}_{\mathrm{r}} \quad$ Tail Froude number of the main channel

To describe the variation of $S_{v} / S_{v t}$ with $Q_{r}$, Table 1 shows the results for different $\alpha$ and $B_{r}$. The following figures show sample results for the case of $B_{r}$ of 0.3 .

Table 1: Ratios sediment volume with different parameters

\begin{tabular}{ccccccc}
\hline$\alpha$ & $\mathrm{Q}_{\mathrm{r}}$ & $\begin{array}{c}\text { The main } \\
\text { channel } \\
\text { downstream }\end{array}$ & $\mathrm{B}_{\mathrm{r}}=0.6$ & $\mathrm{~B}_{\mathrm{r}}=0.5$ & $\mathrm{~B}_{\mathrm{r}}=0.4$ & $\mathrm{~B}_{\mathrm{r}}=0.3$ \\
\cline { 3 - 7 } & & $\mathrm{F}_{\mathrm{r}}$ & $\mathrm{S}_{\mathrm{v}} / \mathrm{S}_{\mathrm{vt}}$ & $\mathrm{S}_{\mathrm{v}} / \mathrm{S}_{\mathrm{vt}}$ & $\mathrm{S}_{\mathrm{v}} / \mathrm{S}_{\mathrm{vt}}$ & $\mathrm{S}_{\mathrm{v}} / \mathrm{S}_{\mathrm{vt}}$ \\
\hline 110 & 0.1 & 0.23 & 0.043 & 0.107 & 0.20122 & 0.274 \\
130 & 0.1 & 0.23 & 0.037 & 0.055 & 0.13415 & 0.177 \\
145 & 0.1 & 0.23 & 0.004 & 0.005 & 0.00732 & 0.01 \\
160 & 0.1 & 0.23 & 0.000 & 0 & 0.00047 & 0.001 \\
170 & 0.1 & 0.23 & 0.000 & 0 & 0.0011 & 0.002 \\
110 & 0.2 & 0.20 & 0.2378 & 0.334 & 0.44146 & 0.53
\end{tabular}




$\begin{array}{lllllll}130 & 0.2 & 0.20 & 0.1780 & 0.277 & 0.36829 & 0.466 \\ 145 & 0.2 & 0.20 & 0.0220 & 0.027 & 0.07561 & 0.085 \\ 160 & 0.2 & 0.20 & 0.0002 & 0.0003 & 0.00197 & 0.0037 \\ 170 & 0.2 & 0.20 & 0.0004 & 0.0006 & 0.00171 & 0.0040 \\ 110 & 0.3 & 0.18 & 0.4878 & 0.604 & 0.72561 & 0.902 \\ 130 & 0.3 & 0.18 & 0.4293 & 0.518 & 0.67317 & 0.795 \\ 145 & 0.3 & 0.18 & 0.1951 & 0.222 & 0.28049 & 0.311 \\ 160 & 0.3 & 0.18 & 0.0028 & 0.008 & 0.00887 & 0.013 \\ 170 & 0.3 & 0.18 & 0.0039 & 0.015 & 0.01829 & 0.043 \\ 110 & 0.4 & 0.16 & 0.905 & 1.07 & 1.29634 & 1.466 \\ 130 & 0.4 & 0.16 & 0.760 & 0.943 & 1.14024 & 1.287 \\ 145 & 0.4 & 0.16 & 0.544 & 0.573 & 0.66341 & 0.726 \\ 160 & 0.4 & 0.16 & 0.012 & 0.014 & 0.0439 & 0.157 \\ 170 & 0.4 & 0.16 & 0.028 & 0.032 & 0.07317 & 0.201\end{array}$

To describe the variation of $S_{v} / S_{v t}$ with $Q_{r}$, Figure. 7 is drawn considering investigated width ratio $\left(B_{r}\right)$ of 0.3 . The intake angle, $110^{\circ}$ gives the highest values of $S_{v} / S_{v t}$ as the maximum value reached 1.466 at a discharge ratio 0.4 . This value decreased gradually until it became 0.274 at a discharge ratio 0.1 . As depicted that increasing the intake angle from $110^{\circ}$ to $160^{\circ}$, decreased $S_{v} / S_{v t}$. The value $S_{v} / S_{v t}$ decreased to 0.157 at discharge ratio 0.4 , while at discharge ratio 0.1 it was 0.001 .

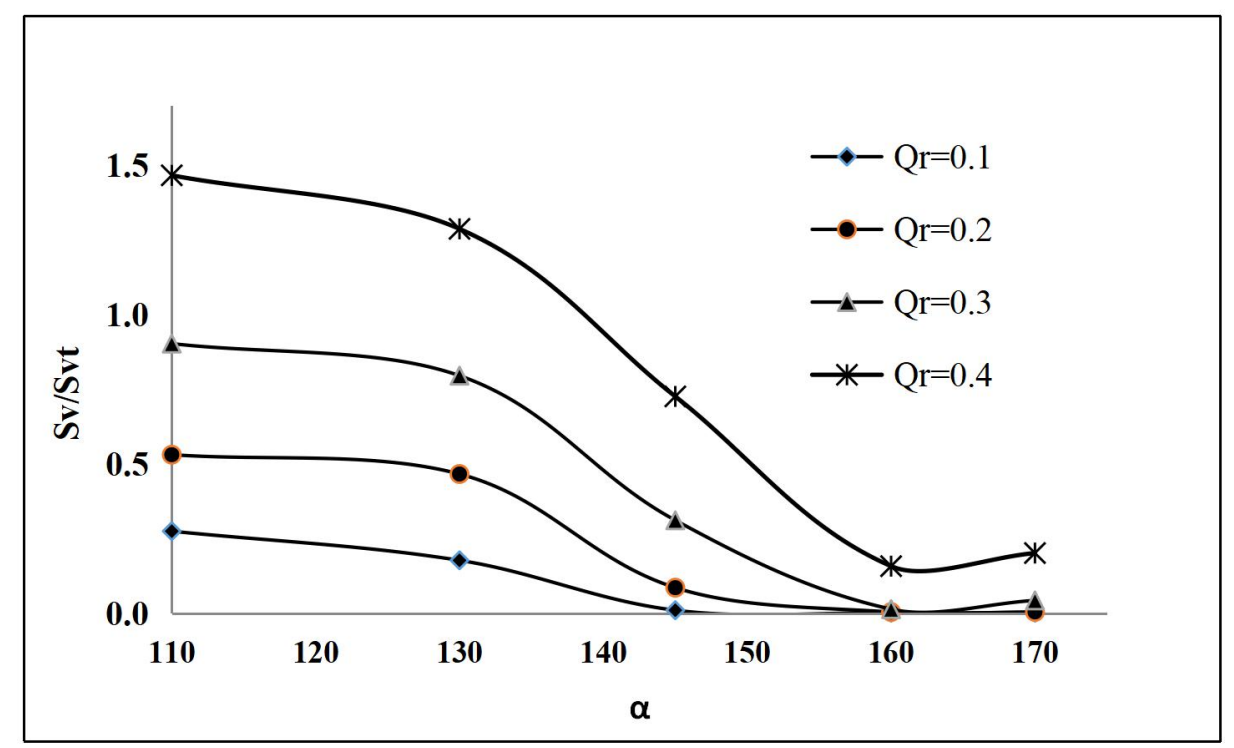

Figure. 7 Relationship between $S_{v} / S_{v t}, Q_{r}$ and $\alpha$ for $B_{r}=0.3$ 
Comparing the angles of different intakes to the width ratio of 0.3 for the highest discharge ratio showed that angle $160^{\circ}$ reduced the volume of diverted sediment material by $89 \%$, while for the lowest discharge ratio was $99.5 \%$.

As depicted for all values of $S_{v} / S_{v t}$, the values $S_{v} / S_{v t}$ are significant until the intake angle $145^{\circ}$. There is no significant difference between the intake angle $(\alpha) 160^{\circ}$ and $170^{\circ}$ at sediment volume reduction for $0.1 \leq \mathrm{Q}_{\mathrm{r}} \leq 0.4$.

As also depicted, $S_{v} / S_{v t}$ is increasing proportionally to discharge ratio $\left(Q_{\mathrm{r}}\right)$ while inversely to the intake angle. The intake angle $160^{\circ}$ gave the minimum sediment diversion $S_{v} / S_{v t}$ for all the discharge ratios.

Results indicated that the discharge ratio of 0.1 for the angle $160^{\circ}$ do not divert sediments inside the lateral intake.

To describe the variation of $d_{s} / y_{t}$ with $Q_{r}$, Figure 8 is drawn considering investigated width ratio $\left(B_{r}\right)$ of 0.3 . The intake angle $110^{\circ}$ gave the highest values $d_{s} / y_{t}$ as the maximum value reached 0.71 at a discharge ratio 0.4 . This value decreased gradually until it became 0.24 at a discharge ratio 0.1 . Increasing the intake angle from $110^{\circ}$ to $160^{\circ}$, decreased $S_{v} / S_{v t}$ to 0.29 at discharge ratio 0.4 , while at discharge ratio 0.1 it was 0.10 .

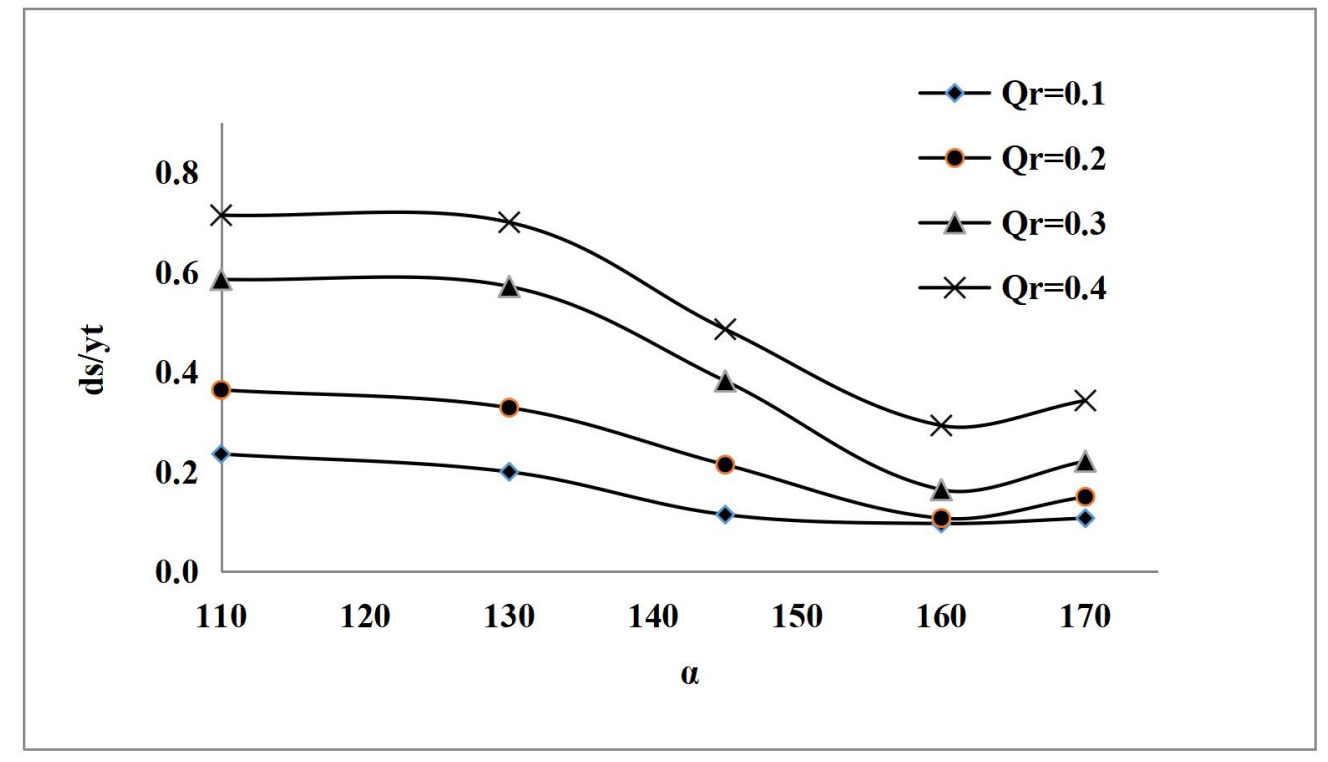

Figure. 8. Relationship between $d_{s} / y_{t}$ and $\alpha$ for $B_{r}=0.3$

It is seen that $d_{s} / y_{t}$ increased as the discharge ratio $\left(Q_{r}\right)$ increased while $d_{s} / y_{t}$ decreased as the intake angle increased. It is clear there is an indirect relationship between intake angles and $d_{s} / y_{t}$. Increasing the intake angle reduces the scour beside the intake channel. Results 
showed that the intake angle of $160^{\circ}$ gave the minimum scour beside the intake for all discharge ratios.

Figs. (9 and 10) represent the noticed variation of non-dimensional length $L_{s} / b_{d}$ and width $\mathrm{w}_{\max } / \mathrm{b}_{\mathrm{d}}$ of separation zone with the intake angles for different discharge ratios and width ratio of 0.3 .

For intake angle $110^{\circ}$, the relative separation length and width have maximum value as the maximum relative separation length and width reached 4.0 and 0.43 respectively at discharge ratio 0.1 . These values gradually decreased until it became 1.36 and 0.21 respectively at discharge ratio 0.4 .

It is seen that increasing the intake angle from $110^{\circ}$ to $160^{\circ}$, reduced the separation length and width along the intake channel as the maximum relative separation length and width decreased to 1.14 and 0.11 respectively at discharge ratio 0.1 , while the separation zone completely vanishes at discharge ratio 0.4 .

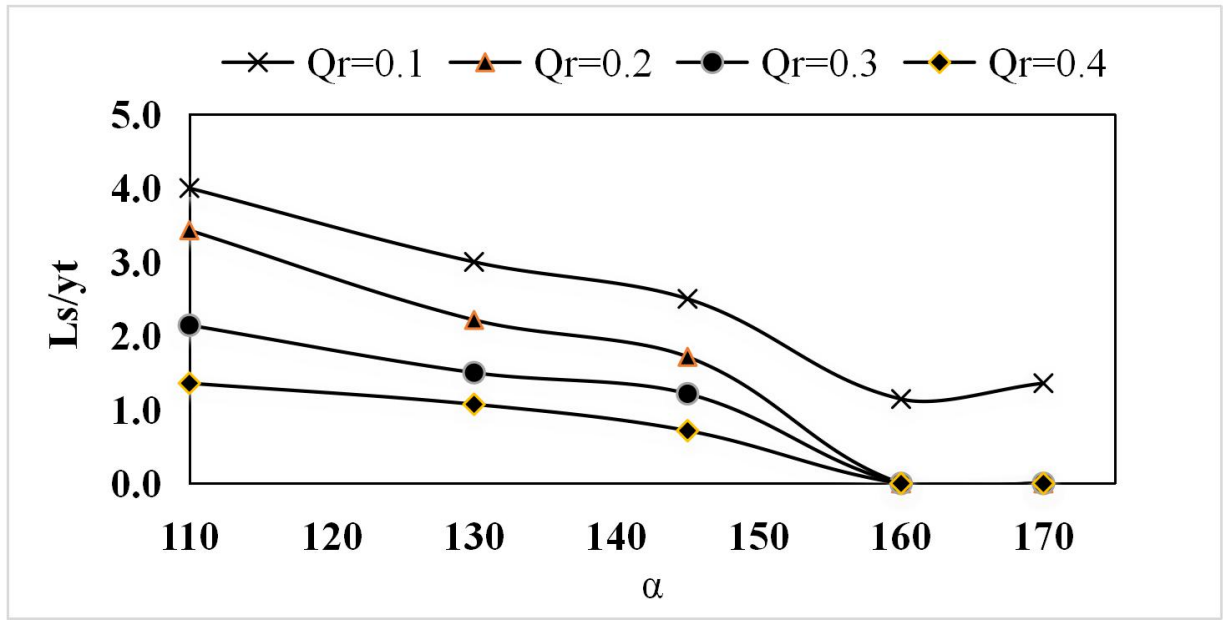

Fig.9. Relationship between $\mathrm{L}_{\mathrm{s}} / y_{\mathrm{t}}$ and $\alpha$ for $\mathrm{B}_{\mathrm{r}}=0.3$ 


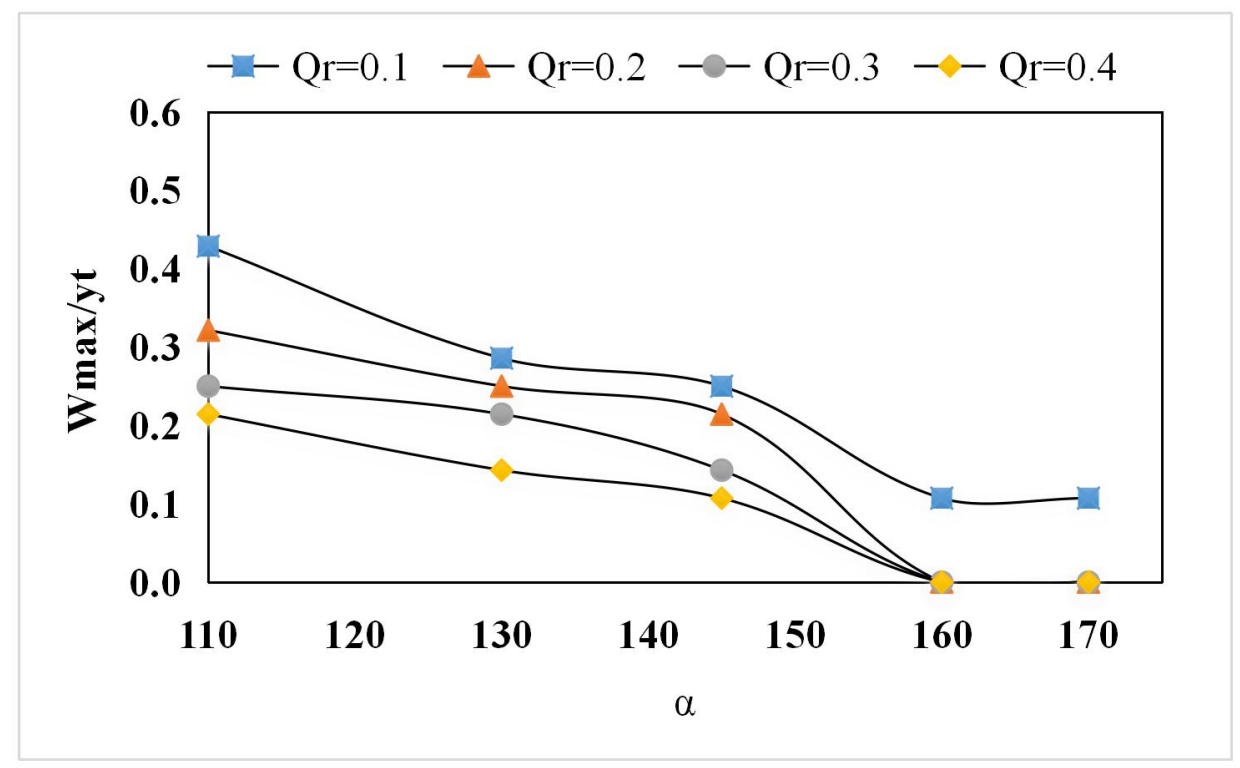

Fig.10. Relationship between $w_{\max } / y_{t}$ and $\alpha$ for $B_{r}=0.3$

Studying the discharge ratio and its effect on the separation zone revealed that there is a direct relationship between the length and width of the separation zone, while there is an inverse relationship between separation zone and the discharge ratios. It is clear that increasing the width ratios leads to an increase in the length and width of separation zone. There exists a direct relationship between the width ratio and the separation zone. This could be close to that concluded by (Amin A., et al. 2014) .

To describe the variation of contraction coefficient $\mathrm{Cc}$ with the intake angles for different discharges, Table 2 shows the results for different width ratios $(\mathrm{Br})$ and the following figures show the sample results for $\mathrm{Br}$ of 0.3 .

Table 2: Contraction coefficient with different parameters

\begin{tabular}{ccccccc}
\hline & & $\begin{array}{c}\text { The main } \\
\text { channel } \\
\text { downstream }\end{array}$ & $\mathrm{Br}=0.6$ & $\mathrm{Br}=0.5$ & $\mathrm{Br}=0.4$ & $\mathrm{Br}=0.3$ \\
\cline { 4 - 7 } & $\mathrm{Q}_{\mathrm{r}}$ & $\mathrm{F}_{\mathrm{r}}$ & $\mathrm{Cc}$ & $\mathrm{Cc}$ & $\mathrm{Cc}$ & $\mathrm{Cc}$ \\
\hline 110.00 & 0.1 & 0.23 & 0.361 & 0.383 & 0.5 & 0.667 \\
130.00 & 0.1 & 0.23 & 0.431 & 0.45 & 0.583 & 0.778 \\
145.00 & 0.1 & 0.23 & 0.611 & 0.633 & 0.625 & 0.806 \\
160.00 & 0.1 & 0.23 & 0.875 & 0.867 & 0.875 & 0.917 \\
170.00 & 0.1 & 0.23 & 0.694 & 0.783 & 0.75 & 0.917
\end{tabular}




\begin{tabular}{ccccccc}
110.00 & 0.2 & 0.20 & 0.486 & 0.517 & 0.625 & 0.75 \\
130.00 & 0.2 & 0.20 & 0.583 & 0.6 & 0.688 & 0.806 \\
145.00 & 0.2 & 0.20 & 0.722 & 0.717 & 0.729 & 0.833 \\
160.00 & 0.2 & 0.20 & 0.903 & 0.900 & 0.896 & 1 \\
170.00 & 0.2 & 0.20 & 0.75 & 0.85 & 0.833 & 1 \\
110.00 & 0.3 & 0.18 & 0.597 & 0.65 & 0.729 & 0.806 \\
130.00 & 0.3 & 0.18 & 0.681 & 0.717 & 0.771 & 0.833 \\
145.00 & 0.3 & 0.18 & 0.792 & 0.783 & 0.833 & 0.889 \\
160.00 & 0.3 & 0.18 & 0.958 & 0.983 & 1 & 1 \\
170.00 & 0.3 & 0.18 & 0.833 & 0.967 & 1 & 1 \\
110.00 & 0.4 & 0.16 & 0.667 & 0.683 & 0.792 & 0.833 \\
130.00 & 0.4 & 0.16 & 0.722 & 0.8 & 0.833 & 0.889 \\
145.00 & 0.4 & 0.16 & 0.847 & 0.85 & 0.896 & 0.917 \\
160.00 & 0.4 & 0.16 & 0.986 & 1 & 1 & 1 \\
170.00 & 0.4 & 0.16 & 0.903 & 1 & 1 & 1 \\
\hline
\end{tabular}

Figure 11. represents the variation of contraction coefficient $\mathrm{Cc}$ with the intake angles for different discharges. It is obvious that the contraction coefficient reached 1.0 at the intake angle $160^{\circ}$. This result reveals that the contraction coefficient $\mathrm{Cc}$ increases as the intake angle increases and this result valid until $160^{\circ}$, while at the intake angle $170^{\circ}$ happen inflation in all most cases.

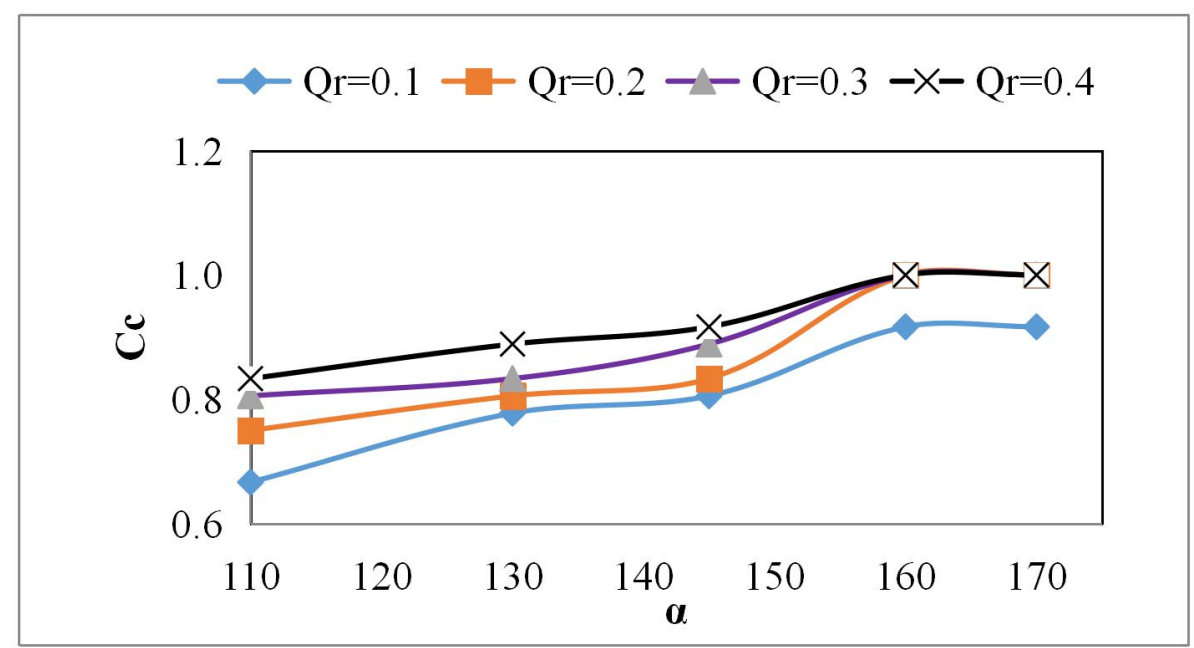

Fig.11. Relationship between $\mathrm{Cc}$ and $\alpha$ for $\mathrm{B}_{\mathrm{r}}=0.3$ 
This indicates that decreasing the width of the separation zone, the effective width increases and therefore the flow discharge inside the intake improved. It is clear that, the intake angle has a direct relationship with contraction coefficient, while it has an indirect relationship with separation zone. Also, as increasing the intake angle a movement happens to the separation zone inside the intake that reduces the area of the separation zone which defined by (Pirzadeh B., Shamloo H. 2007) the area of reduced pressure and re-circulating water with low velocities; therefore, it has a strong sediment deposition potential in which sediment particles enter the intake channel.

\section{Sensitivity Analysis}

Ranking Parameters for uncertainty by (Verbeeck et al. 2006) showed that the model input parameters can be ranked for uncertainty using the technique of multiple linear regression. This analysis estimates the uncertainty contribution of each one of the input parameters to the overall input uncertainty. The least square linearization considered one of the most power full methods used to rank the influencing parameters according to their contribution on the output or the target equation. This method has the advantage of varying all input parameters at the same time unlike other methods where only one parameter can be perturbed at a time. LSL method is a multiple regression between the parameter deviation from the mean and the output (Lei and schilling 1996). The following equations provide a mathematical background to the LSL method which is in essence a multiple regression between the parameter deviation from the mean and the output. Consider a variable, $y$, that depends on a number of independent variables, v1, v2,.., vn.

The variation of $y$ a function of small variations in independent variables can be expressed as:

$$
\Delta y=\frac{\partial y}{\partial v_{1}} \Delta v_{1}+\frac{\partial y}{\partial v_{2}} \Delta v_{2}+\ldots \ldots+\frac{\partial y}{\partial v_{n}} \Delta v_{n}
$$

Where $\Delta \boldsymbol{v}_{\boldsymbol{i}}$ is defined as the difference between $\boldsymbol{v}_{\boldsymbol{i}}$, the random chosen sample of parameter $\mathrm{i}$ and $\overline{\boldsymbol{v}_{\boldsymbol{i}}}$, the mean value of parameter $\mathrm{i}$ of all the random samples, and $n$ is total number of input parameter

$$
\Delta v_{i}=v_{i}-\bar{v}_{i}
$$

If $\mathrm{y}$ is considered as $\bar{y}+\Delta y$, then: 


$$
y=\bar{y}+\frac{\partial y}{\partial v_{1}} \Delta v_{1}+\frac{\partial y}{\partial v_{2}} \Delta v_{2}+\ldots \ldots+\frac{\partial y}{\partial v_{n}} \Delta v_{n}
$$

When $\mathrm{m}$ Monte Carlo simulations are carried out, $\Delta \mathrm{vi}$ for each parameter and the model output y are calculated for each simulation. Next, a multi-linear regression on the obtained dataset is performed. The $\Delta v$ vi values are considered as independent variables and the output $y$ is the dependent variable. This gives the following regression equation:

$$
y \approx b+w_{1} v_{1}+w_{2} v_{2}+\ldots \ldots+w_{n} v_{n}
$$

The regression coefficients (wi) are estimated by minimizing the sum of squared errors. Comparing this with Equation 4, it can been seen that the coefficients w1, w2,.., wn are estimates of the partial derivatives of $y$ with respect to vi and $b$ is an estimate of the value of $y$ at default parameter values (i.e., when $\Delta v i=0$ for all i).

If the uncertainties of the independent parameters are statistically independent, the overall variance of the model output $\operatorname{Var}(\Delta y)$ can be calculated as:

$$
\operatorname{Var}(\Delta y) \approx \sum_{i=1}^{n} w_{i}^{2} \cdot \operatorname{Var}\left(\Delta v_{i}\right)
$$

Where: $\operatorname{Var}(\Delta v i)$ is the variance of the calculated difference $\Delta v i$.

Based on the regression coefficients and the variations of the parameter uncertainties, the sensitivity coefficient of each parameter i ( $\mathrm{SVi}$ ) can be approximated as:

$$
S_{v_{i}}=\frac{w_{i}^{2} \cdot \operatorname{Var}\left(\Delta v_{i}\right)}{\operatorname{Var}(\Delta y)} * 100 \%
$$

From previous research and dimension analysis, the sediment ratio diverted to the lateral intake can be assumed to be a function of the intake angle and the discharge and the width ratios as follows:

$$
\begin{aligned}
& S V r=\mathrm{F}(\alpha, Q r, B r) \\
& C c=F(\alpha, Q r, B r)
\end{aligned}
$$

where Svr is the sediment ratio diverted to the lateral intake and $\mathrm{Cc}$ is contraction coefficient. Table shows the regression coefficients wi obtained through multiple linear regression, the variance $\sigma_{\delta_{v_{i}}}^{2}$ for the difference between the mean value of input random realizations and the chosen realization. These values are inserted in Eq. (6) to obtain the required input parameter sensitivity. It is found that the diverted sediment Svr is most sensitive to the intake angle with $55.3 \%$ influence, followed by the discharge ratio with about $40.2 \%$ and by the width ratio with about $4.5 \%$. Other input parameters such the width ratio had lower contribution to 
sediment ratio with about $4.5 \%$ influence, whereas It is found that the contraction coefficient $\mathrm{Cc}$ is most sensitive to the intake angle with $56.8 \%$ influence, followed by the discharge and width ratios with about $27.5 \%$ and $15.7 \%$ respectively.

Table 3 : LSL regression coefficients and sensitivity results

\begin{tabular}{|c|c|c|c|}
\hline \multicolumn{4}{|c|}{$S V r$} \\
\hline & $\alpha$ & Qr & $\mathrm{Br}$ \\
\hline$w_{i}$ & -0.011 & 1.791199 & -0.60247 \\
\hline$\sigma_{\delta_{v_{i}}}^{2}$ & 461.7722 & 0.012658 & 0.012658 \\
\hline$S_{V_{i}}$ & 55.3 & 40.2 & 4.5 \\
\hline \multicolumn{4}{|c|}{$C c$} \\
\hline & $\alpha$ & Qr & $\mathrm{Br}$ \\
\hline$w_{i}$ & 0.005253 & 0.698611 & -0.52667 \\
\hline$\sigma_{\delta_{v_{i}}}^{2}$ & 461.7722 & 0.012658 & 0.012658 \\
\hline Cc & 56.8 & 27.5 & 15.7 \\
\hline
\end{tabular}

\section{Artificial Neural Networks}

Artificial neural networks (ANN), computer models which belong to the domain of artificial intelligence are mathematical models that imitate the recognition and generalization capabilities of human brain (Chen et.al 2012).

Recently, artificial neural networks (ANN) models have been used widely and have been accepted as technology used to simulate the undefined and nonlinear problems which describe a wide range of problems in several areas of civil engineering. (Mabel et. al 2008)

ANN is an important and very powerful tool to be used specially when dealing with nonlinear problems for forecasting the target value with acceptable error value on the other side it does not need complicated computational process or large programing effort since they can learn by training the input data and the ANN models are integrated to an easy to use programing tool box. (Pengzhen Lu et al. 2012) 
In the current study the ANN-based models will be developed using the MATLAB ANNfitting tool box. A multi hidden layer feed-forward neural network was trained by back propagation algorithm using iterative weight adjustment procedures and Levenberg-Marquarts activation function. (Sheikh et al. 2012).

\subsection{Evaluating Predictive Model Performance}

The developed Predictive models works on constructive and feedback principle, once you build a model you must score the model to check the accuracy and get the feedback from the statistical performance indicators, make some improvements and try again until you achieve an acceptable accuracy, (Steel 1960).

The developed ANN-models will be scored on a set of performance indicators. These indicators are the coefficient of determination $\left(\mathrm{R}^{2}\right)$, root mean square error (RMSE),

These indicators are calculated from the predicted value $(\mathrm{P})$ and observed value $(\mathrm{T})$ and can be expressed by the following formulas:

\subsubsection{Determination coefficient}

Statistical indicator used to check the statistical models whose main purpose is prediction of future outcomes. This coefficient provides a measure of how well observed outcomes are replicated by the model, based on the proportion of total variation of outcomes explained by the model (Glantz et al. 1990). And will be calculated using the following formula:

$$
R_{i}{ }^{2}=\left(\frac{\frac{1}{n} \sum_{j=1}^{n}\left(T_{j}-\bar{T}\right)\left(P_{(i j)}-\bar{P}\right)}{\sqrt{\sum_{j=1}^{n}\left(T_{j}-\bar{T}\right)^{2} / n} \sqrt{\sum_{j=1}^{n}\left(P_{(i j)}-\bar{P}\right)^{2} / n}}\right)^{2}
$$

\subsubsection{Root Mean Squared Error}

RMSE is the most popular evaluation metric used in regression problems. It follows an assumption that errors are unbiased and follow a normal distribution. Here are the key points to consider on RMSE (Witten 2016):

1. The power of 'square root' empowers this metric to show large number deviations.

2. The 'squared' nature of this metric helps to deliver more robust results which prevents cancelling the positive and negative error values. In other words, this metric aptly displays the plausible magnitude of error term. 
3. It avoids the use of absolute error values which is highly undesirable in mathematical calculations.

4. When we have more samples, reconstructing the error distribution using RMSE is considered to be more reliable.

5. RMSE is highly affected by outlier values. Hence, make sure you've removed outliers from your data set prior to using this metric.

6. As compared to mean absolute error, RMSE gives higher weightage and punishes large errors.

The RMSE metric is given by:

$$
R M S E=\frac{\sum_{j=1}^{n}\left(T_{i}-P_{i}\right)^{2}}{n}
$$

\subsection{Developed ANN Models}

Two ANN-based models were developed using the experimental results combinations for the most influential parameters on the sediment ratio diverted to the lateral intake $\left(\mathrm{S}_{\mathrm{vr}}\right)$ and contraction coefficient $\left(C_{c}\right)$ Chosen from Table . No strong correlation or interdependency was found among the predictor variables, the database was randomly divided into training and testing subsets. The selection was made such that the descriptive statistical parameters (mean and standard deviation) of both the training and testing and validation subsets were consistent. Out of the 80 values measured for building each model, 60 (75\%) were used to develop the models, and $20(25 \%)$ were used to test the developed models.

Numerous ANN models, each differing in one or more of the following Aspects: number of input variables, number of hidden layer neurons, order of the data set and type of weight adjusting procedure were developed in an effort to arrive at a most optimally trained ANN model. For every ANN model, the data set was shuffled randomly and it was ensured that the data points with highest and lowest input/output variables were in the training set rather than in the testing set. This would avoid the need for extrapolation in the testing process. Using the optimum parameter settings for the ANN model the developed ANN models for the prediction of $\left(S_{v r}\right)$ and $\left(C_{c}\right)$ had high scores and low prediction errors.

Table. shows a general statistical overview for the performance of the developed ANN models for prediction of $\left(\mathrm{S}_{\mathrm{vr}}\right)$ and $\left(\mathrm{C}_{\mathrm{c}}\right)$. The ANN models for predicting Svr and $C c$ performed well for 
both the training and testing datasets, with an average $\mathrm{R}^{2}$ of 0.98 for training and of 0.96 for testing datasets. The error measures, RMSE shows low values for training and testing datasets.

Table.4: Statistical performance of developed ANN prediction model

\begin{tabular}{cccc}
\hline Model & Data Partitioning & $\mathbf{R}^{2}$ & RMSE \\
\hline $\mathrm{S}_{\mathrm{vr}}$ & Train & 0.98 & $1.65 \mathrm{E}-04$ \\
& Test & 0.97 & $1.85 \mathrm{E}-04$ \\
\hline \multirow{2}{*}{$\mathrm{C}_{\mathrm{c}}$} & Train & 0.97 & $7.08 \mathrm{E}-04$ \\
& Test & 0.96 & $9.18 \mathrm{E}-04$ \\
\hline
\end{tabular}

Fig.12 and Fig.13 shows Measured Sediment ratio Svr and Contraction Coefficient $\boldsymbol{C} \boldsymbol{c}$ versus that predicted by the ANN-model respectively. It is clear that the ANN models for Svr and $\boldsymbol{C c}$ showed excellent agreement with slight errors and with no significant over- or underpredictions. 


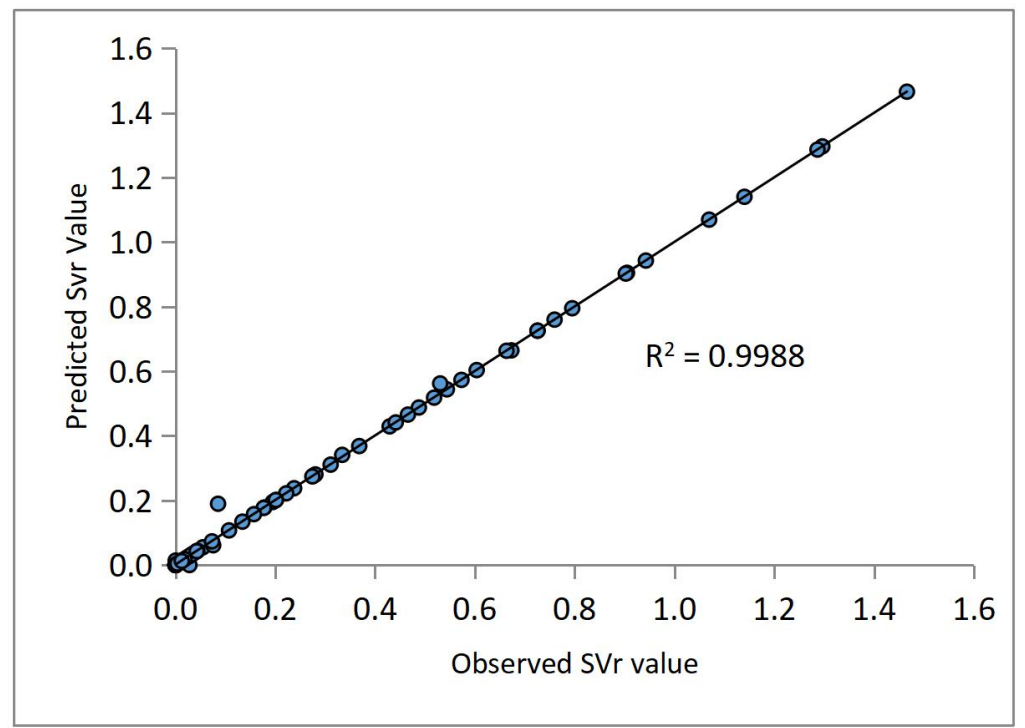

Fig.12: Measured Sediment ratio Svr versus that predicted by the ANN-model

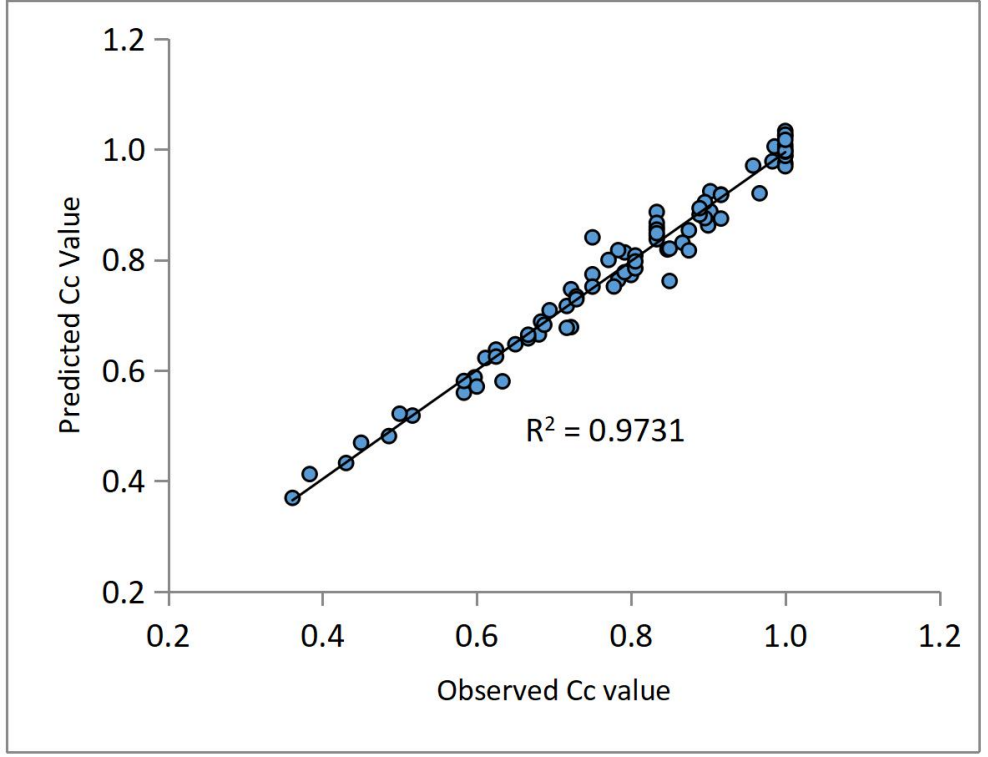

Fig.13: Measured Contraction Coefficient $C c$ versus that predicted by the ANN-model

\subsection{Parametric analysis using the developed ANN models}

This section is intended to show the robustness of the developed ANN models and how they provide correct physical trends for the predicted the sediment ratio diverted to the lateral intake $\left(\mathrm{S}_{\mathrm{vr}}\right)$ and contraction coefficient $\left(\mathrm{C}_{\mathrm{c}}\right)$ versus input parameters as confirmed and shown from the measured data.

The predicted sediment ratio and contraction coefficient as calculated by the ANN is plotted against intake angle.

It is observed that the increase in intake angle causes an observed decrease in the sediment ratio diverted to the lateral intake $\left(\mathrm{S}_{\mathrm{vr}}\right)$ to reach an optimum angle of 164 and the an inverse 
trend will happen also an observed increase in the value of the contraction coefficient $\left(\mathrm{C}_{\mathrm{c}}\right)$ with the increase of angle as show Fig.14 and Fig.15.

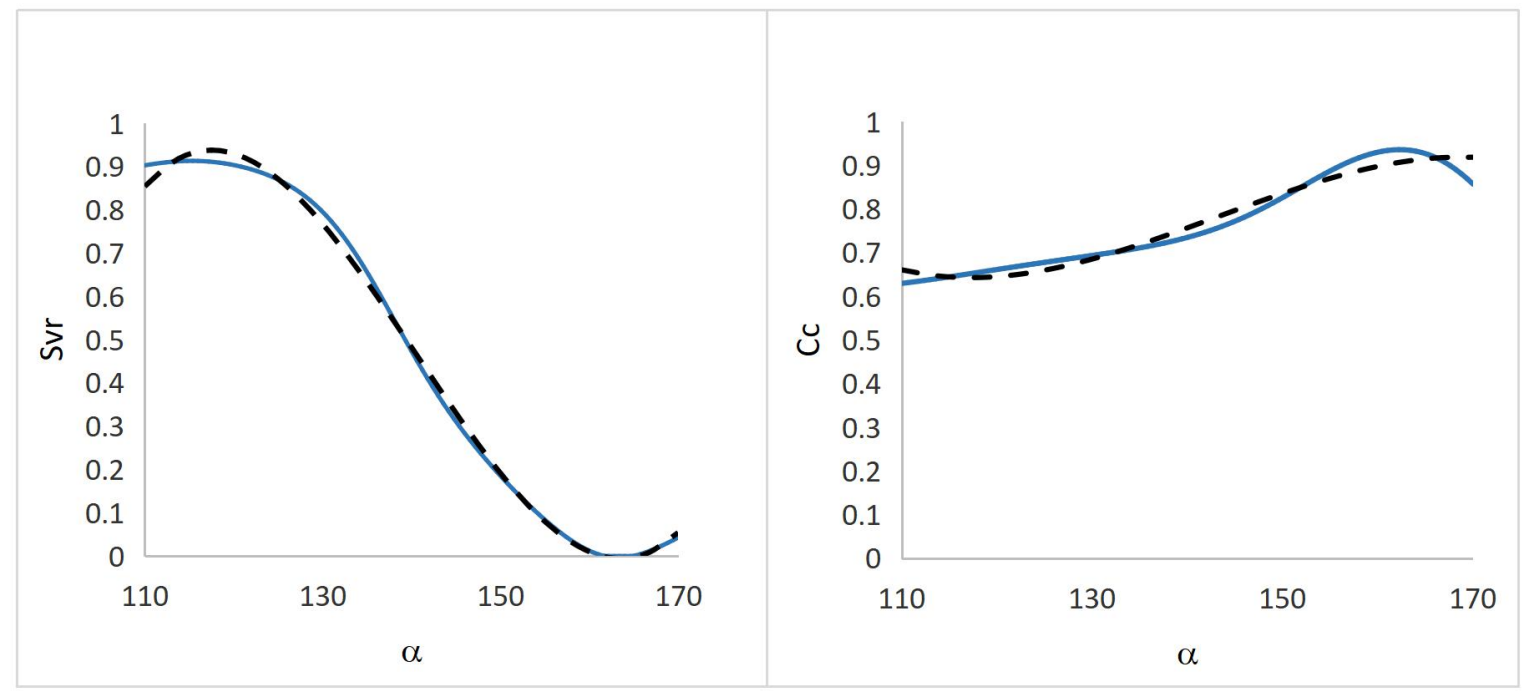

Fig.14: Variation of $S_{v r}$ and $C_{c}$ with angle of inclination

It is observed that the increase in intake (Qr) causes an observed increase in the sediment ratio diverted to the lateral intake $\left(\mathrm{S}_{\mathrm{vr}}\right)$ to reach also an observed increase in the value of the contraction coefficient $\left(\mathrm{C}_{\mathrm{c}}\right)$ with the increase of Qr.

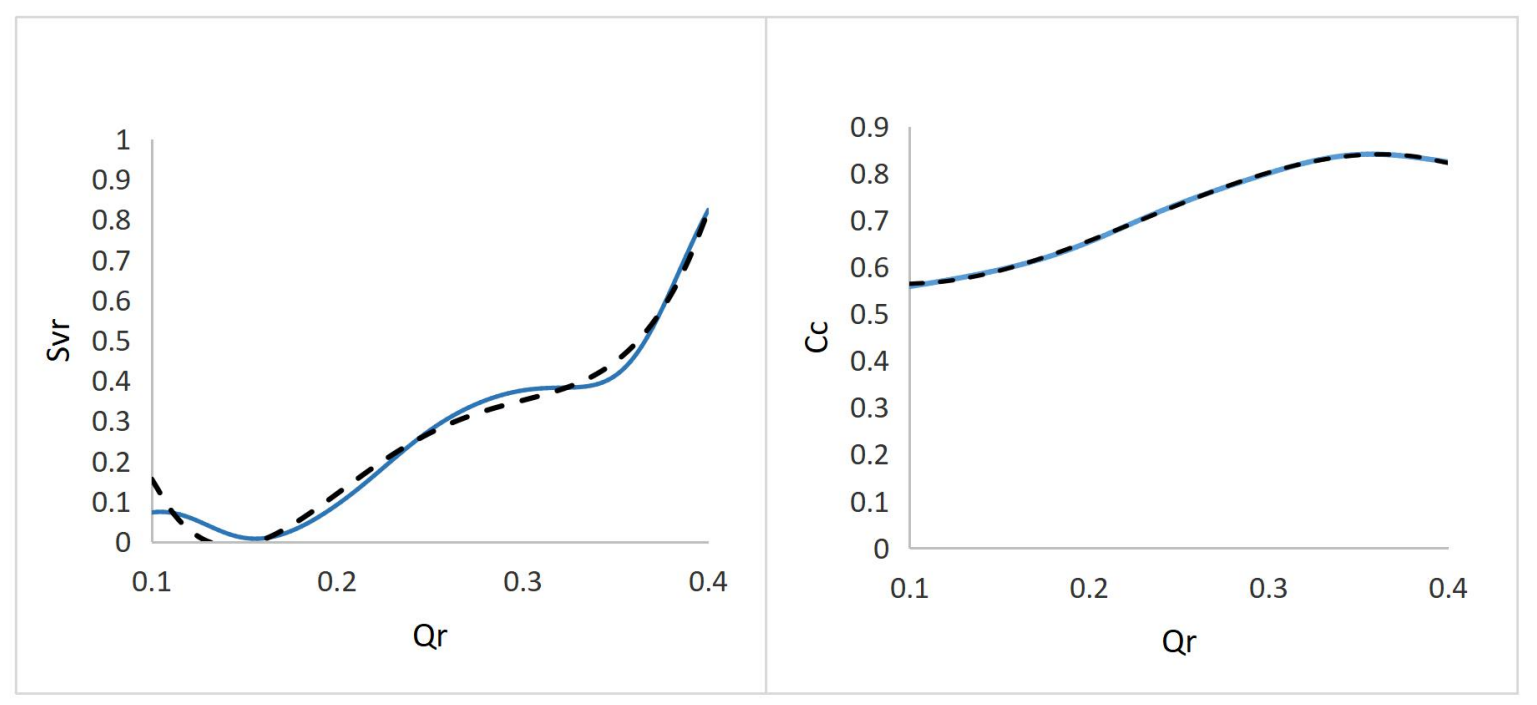

Fig.15: Variation of $S_{v r}$ and $C_{c}$ with $Q r$

It is observed that the increase in intake $\mathrm{Br}$ causes an observed decrease in the sediment ratio diverted to the lateral intake $\left(\mathrm{S}_{\mathrm{vr}}\right)$ to reach also an observed decrease in the value of the contraction coefficient $\left(\mathrm{C}_{\mathrm{c}}\right)$ with the increase of $\mathrm{Qr}$, as show Figure 16. 


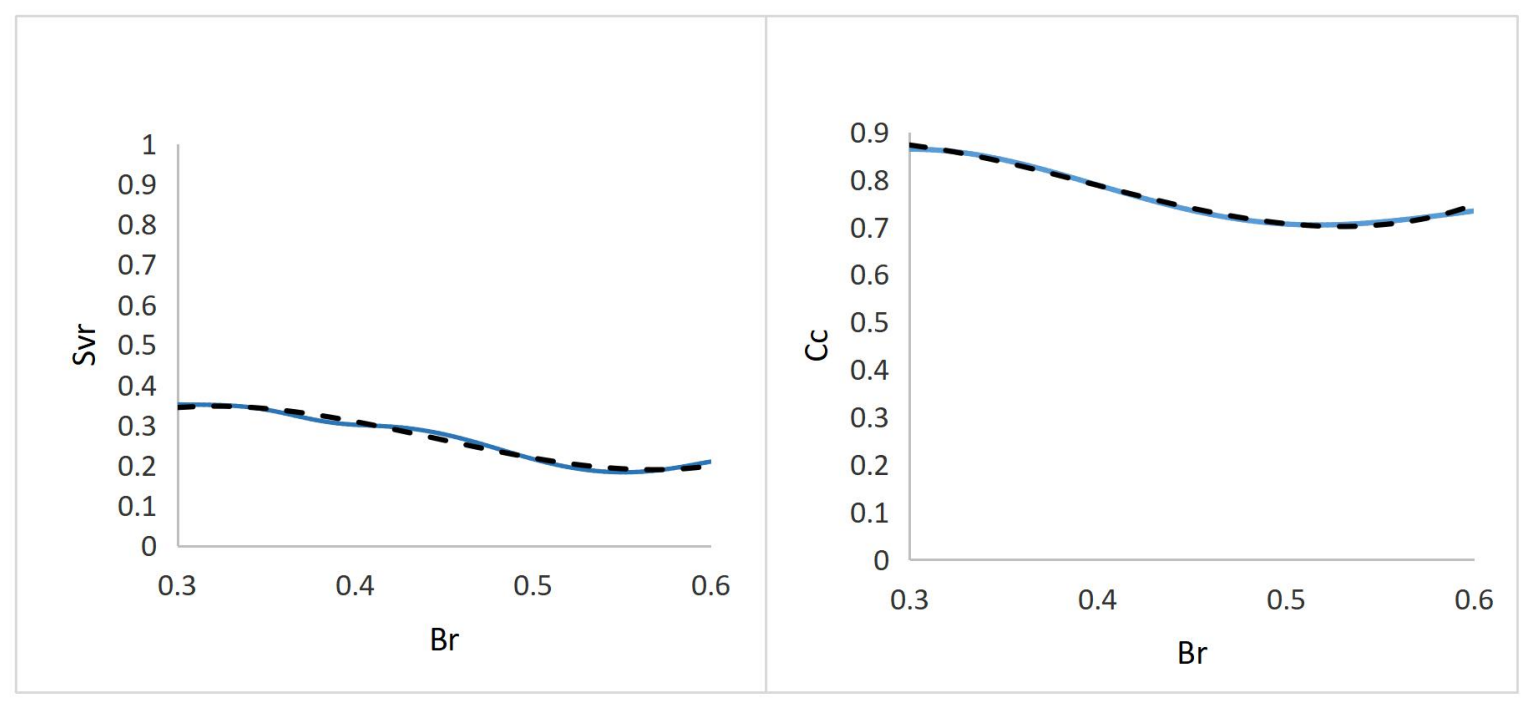

Fig.16: Variation of Svr and $\mathrm{CC}$ with angle of $\mathrm{Br}$

\section{Conclusion}

This research focused on the study of the effect of different values of the intake angles on the sediment volume and flow pattern inside the intake channel by testing a wider range of the dimensions and the intake angles using physical model tests and ANN-based models.

Two ANN-based models were developed using the experimental results combinations for the most influential parameters on the sediment ratio diverted to the lateral intake (Svr) and contraction coefficient $(\mathrm{Cc})$

The ANN models for predicting Svr and $C c$ performed well for both the training and testing datasets, with an average R2 of 0.98 . The error measures, RMSE shows low magnitude of error

Physical Model results showed that the intake angle has a significant influence on controlling sediment diversion and enhancing flow discharge inside the lateral intake channel under different discharge ratios. The intake angle $160^{\circ}$ gives better results compared to the other angles and there is no significant difference between it and $170^{\circ}$. The intake angle $(\alpha) 160^{\circ}$ gives $89 \%$ sediment volume reduction compared to $\alpha$ of $110^{\circ}$ whereas the intake angle $(\alpha)$ $170^{\circ}$ gives $86 \%$ sediment volume reduction compared to $\alpha$ of $110^{\circ}$ for the highest discharge.

In order to validate the developed ANN Models and showing the robustness of the developed and how they provide correct physical trends for the predicted the sediment ratio diverted to the lateral intake (Svr) and contraction coefficient $(\mathrm{Cc})$ with the input parameters Parametric 
Study had been conducted and trend lines had been drawn for the developed models and the physical models showing complete matching with a very low magnitude of error

Developed ANN-based Models showed that the predicted sediment ratio and contraction coefficient as calculated by ANN-based model observed that the increase in intake angle causes an observed decrease in the sediment ratio diverted to the lateral intake (Svr) to reach an optimum angle of 164 and the an inverse trend will happen also an observed increase in the value of the contraction coefficient $(\mathrm{Cc})$ with the increase of angle.

From ANN-based and physical models observed that the optimum lateral intake angle is $164^{\circ}$ for all results also the intake angle range between 150 to 170 we can neglect effect $\mathrm{Br}$.

This research revealed that as increasing lateral intake angle the sediment diversion reduced until the optimum intake angle $164^{\circ}$ and then with increasing the intake angle increase the sediment at the range between $164^{\circ}$ to $170^{\circ}$. The experimental tests results indicated that the separation zone vanishes at the highest flow discharge ratios at the angles of the intake $160^{\circ}$ and $170^{\circ}$.

Both intake angles $160^{\circ}$ give maximum flow discharge and minimum sediment diversion for all investigated discharges.

From ANN-based and physical models, it is found that the diverted sediment Svr is most sensitive to the intake angle with 55.3\% influence, followed by the discharge ratio with about $40.2 \%$ and by the width ratio with about $4.5 \%$. Other input parameters such the width ratio had lower contribution to sediment ratio with about $4.5 \%$ influence, whereas It is found that the contraction coefficient $\mathrm{Cc}$ is most sensitive to the intake angle with $56.8 \%$ influence, followed by the discharge and width ratios with about $27.5 \%$ and $15.7 \%$ respectively. These values have been verified using the parametric study performed in the last section also the relation trends have been tested to know the direct relation shape and effect as soon as the correlation.

\section{Acknowledgement}

The authors are so grateful to the Hydraulics Research Institute (HRI), National Water Research Center, of Egypt for their support to this study. This research conducted through the technical cooperation established between HRI and Irrigation and Hydraulics Department, 
Faculty of Engineering, Cairo University. Authors gratefully acknowledge the collaboration and effort offered by all staff members of HRI.

\section{List Of Symbols}

\section{Units}

$\mathrm{b}_{\mathrm{m}}$ : Main channel width

$b_{d}$ : Intake channel width

$\mathrm{d}_{\mathrm{s}}$ : Maximum scour depth at the front of the intake

$\mathrm{D}_{50}$ : Median grain size of sediment

Qd: Discharge passing through the intake channel....

$\mathrm{Q}_{\mathrm{m}}$ : Discharge passing through the main channel.

$\mathrm{Q}_{\mathrm{r}}$ : Relative discharge $=\mathrm{Q}_{\mathrm{d}} / \mathrm{Q}_{\mathrm{m}}$

$\mathrm{S}_{\mathrm{V}}$ : Volume of sediment entering the intake channel

$\mathrm{S}_{\mathrm{Vt}}$ : Volume of sediment column.

$\alpha$ : Later intake angle

$\mathrm{Y}_{\mathrm{t}}$ : Tailwater depth of the main channel.

$\overline{\mathrm{U}}$ : Mean flow velocity of the main channel.

$\mathrm{V}_{\mathrm{b}}$ : Velocity near bed inside intake.

$\mathrm{L}_{\mathrm{S}}$ : Separation length

$\mathrm{w}_{\max }:$ Maximum separation width

\section{References}

[1] Afrouz A.,(2015) "Effect Study of Water Intaking Angle Through Flow Regime At Straight Canal”, Larhyss Journal, University of Biskra, Algeria, Vol. 23, pp. 203-211.

[2] Amin A., Najaf H., Mohammad and Ali P.,( 2014). "The Consequences of Varying The Width Ratio Parameter of The Lateral Water Intake Structure to The Main Canal”, AELIS, India, Vol. 3, pp. 48-54,. 
[3] Pirzadeh B. and Shamloo H.,(2007). "Investigation of Characteristics of Separation Zones in T-Junctions", 12th WSEAS Int. Conf. on Applied Mathematics, Cairo, Egypt.

[4] Vanoni A.,(2006). "Sedimentation Engineering: Manuals and Reports on Engineering Practice", ASCE publication, No. 54, New York,

[5] Amin A.,(2005). "Study of Sedimentation At River Side Intakes", Thesis, Egypt.

[6] Neary V.S., Sotiropoulos F. and Odgaard A.J.,(1999)."Three-Dimensional Numerical Model of Lateral-Intake Inflows", Journal of Hydraulic Engineering, ASCE, Vol. 125 pp. 126-140.

[7] Novak P., Moffat A.I.B., Nalluri C., and Narayanan R.,(1999)."Hydraulic Structures" 4th Edition Handbook, Unwin Hyman, London.

[8] Neary V. S. and Odgaard A. J.,(1993)."Three-dimensional Flow Structure at Open Channel Diversions", Journal of Hydraulic Engineering, ASCE, pp. 119, No. 11.

[9] Raudkivi A.J.,(1993). "Sedimentation: Exclusion and Removal of Sediment from Diverted Water", Handbook, Balkema, Netherlands.

[10] Razvan E.,(1989)."River Intakes and Diversion Dams", Handbook, Elsevier, Amsterdam

[11] Taylor E.,(1944). "Flow Characteristics at Rectangular Open Channel Junctions", Trans., ASCE, Vol. 109, pp. 893-912.

[12] Verbeeck, H., Samson, R., Verdonck, F., \& Lemeur, R. "Parameter sensitivity and uncertainty of the forest carbon flux model". FORUG: a Monte Carlo analysis. Tree physiology, 26(6), 807-817, 2006.

[13] Lei, J. H., \& Schilling, W. "Preliminary uncertainty analysis-a prerequisite for assessing the predictive uncertainty of hydrologic models." Water Science and Technology, 33(2), 79-90. 1996.

[14] Chen, S., Zheng, Y., Cattani, C., \& Wang, W. "Modeling of biological intelligence for SCM system optimization”. Computational and Mathematical Methods in Medicine, 2012.

[15] Mabel, M. C., \& Fernandez, E. "Analysis of wind power generation and prediction using ANN: A case study.” Renewable energy, 33(5), 986-992, 2008.

[16] Sheikh, S. K., \& Unde, M. G. "Short term load forecasting using ANN technique". International Journal of Engineering Sciences \& Emerging Technologies, 1(2), 97-107, 2012.

[17] Lu, Pengzhen, Shengyong Chen, and Yujun Zheng. "Artificial intelligence in civil engineering." Mathematical Problems in Engineering. 2012.

[18] Steel, R. G., \& Torrie, J. "Principales And Pricedures Of Statistics”. Mcgraw-Hill Book Company, Inc,; New York; Toronto; London, 1960. 
[19] Glantz, S. A., \& Slinker, B. K. "Primer of applied regression and analysis of variance" (No. Sirsi) i9780070234079), 1990.

[20] Legates, D. R., \& McCabe, G. J. "Evaluating the use of (goodness of fit) measures in hydrologic and hydroclimatic model validation". Water resources research, 35(1), 233-24, 1999

[21] Witten, I. H., Frank, E., Hall, M. A., \& Pal, C. J. "Data Mining: Practical machine learning tools and techniques”. Morgan Kaufmann, 2016. 